Disponível em

http://www.anpad.org.br/rac

RAC, Rio de Janeiro, v. 19, n. 3, art. 4, pp. 355-373, Maio/Jun. 2015

http://dx.doi.org/10.1590/1982-7849rac20151450

$($ (c) EY-NO

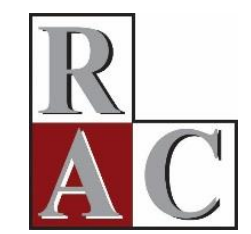

\title{
Doing Business: Uma Análise Comparativa das Regulamentações no BRICS
}

\author{
Doing Business: A Comparative Analysis of the Rules in the BRICS
}

Diego de Queiroz Machado Universidade de Fortaleza - UNIFOR/PPGA

Gleison Mendonça Diniz Universidade de Fortaleza - UNIFOR/PPGA

Mario Henrique Ogasavara Escola Superior de Propaganda e Marketing - ESPM/PMDGI

Fátima Regina Ney Matos Universidade de Fortaleza - UNIFOR/PPGA

Artigo recebido em 15.05.2013. Última versão recebida em 25.06.2014. Aprovado em 09.07.2014. Publicado online em 19.11.2014. 


\title{
Resumo
}

Este trabalho tem como objetivo geral caracterizar os países BRICS (Brasil, Rússia, Índia, China e África do Sul) com base em uma análise de suas regulamentações que interferem na realização de negócios. Para tanto, sua fundamentação teórica consistiu em discussões acerca da teoria institucional e realização de negócios nos países BRICS. Quanto à sua metodologia, foram utilizados dados do projeto Doing Business, examinados mediante técnica de análise de conglomerados, que separou os países em quatro grupos: grupo 1, da África do Sul; grupo 2, da China, Índia e Rússia; grupo 3, do Brasil; e grupo 4, formado, em sua maioria, por países desenvolvidos, sem a presença de algum país do BRICS, sendo este o grupo com os melhores países em facilidade para fazer negócios.

Palavras-chave: regulamentações; teoria institucional; BRICS; doing business; análise de conglomerados.

\begin{abstract}
This study aims to characterize the BRICS countries (Brazil, Russia, India, China and South Africa) based on an analysis of their regulations that affect the conducting of business. To do so, its theoretical foundation consisted of discussions on institutional theory and conducting business in the BRICS countries. Regarding methodology, data came from the Doing Business project, analyzed using a cluster analysis technique. The countries were separated into four groups: group 1, South Africa; group 2, China, India and Russia; group 3, Brazil; and group 4, formed mostly by developed countries, without the presence of any country in the BRICS. Group 4 was found to be the group with the best countries regarding the ease of doing business.
\end{abstract}

Key words: regulations; institutional theory; BRICS; doing business; cluster analysis. 


\section{Introdução}

Definido por Coviello, McDougall e Oviatt (2011, p. 625), como "novos empreendimentos que se envolvem em negócios internacionais", o empreendedorismo internacional tem evoluído demasiadamente a partir do final do século XX, tanto como campo de pesquisa quanto como estratégia organizacional. Essa evolução proporcionou, além do surgimento de inúmeras definições relativas ao tema, a exploração de várias questões relacionadas com esse processo de internacionalização, como diferenças culturais, alianças estratégicas, gestão do conhecimento, aprendizagem tecnológica, entre outras. Neste contexto, a visão baseada em instituições é uma abordagem que traz como contribuição fundamental a inserção de elementos formais e informais na análise da ação organizacional, entre eles, as leis e regulamentações inerentes ao cenário macroeconômico das diversas economias (Peng, Sunny Li, Pinkham, \& Hao, 2009).

Dessa forma, este estudo tem como intuito contribuir com as pesquisas já realizadas no campo do empreendedorismo internacional a partir de uma análise macroeconômica que envolva aspectos institucionais formais de diferentes economias. Entre as economias globais, destacam-se os países emergentes que compõem o acrônimo BRICS - Brasil, Rússia, Índia, China e África do Sul. Conforme Bruton, Ahlstrom e Obloj (2008), esses países se caracterizam por uma expansão econômica orientada para o mercado e que tem como fundamento básico as atividades de empreendedorismo. Sua importância está, de acordo com Wilson (2003), no potencial que tais países carregam para se tornar uma força maior na economia mundial nos próximos anos.

Em razão da inexistência de estudos semelhantes que avaliem as características das regulamentações relativas às atividades de negócios dos países BRICS em comparação com às demais economias globais, este trabalho tem como objetivo geral caracterizar os países BRICS com base em uma análise de regulamentações que interferem na realização de negócios. Para tanto, a realização deste estudo se deu mediante abordagem quantitativa, aplicada a partir da utilização de dados secundários oriundos do projeto Doing Business, cujo banco de dados contém informações relativas às regulamentações aplicadas a pequenas e médias empresas durante seu ciclo de vida em 185 países, entre eles, os países BRICS. Os dados colhidos foram organizados e analisados mediante técnica de análise de conglomerados, que reúne e classifica objetos com base em características dos mesmos.

Assim, espera-se que este trabalho possa contribuir no sentido de promover a discussão do empreendedorismo internacional sob uma perspectiva institucional, analisando as características das regulamentações de diferentes economias. Ademais, mediante aplicação de técnicas de análise estatística, este estudo tem como intuito apresentar uma caracterização das economias globais no que se refere às instituições formais relativas ao exercício dos negócios, principalmente nos países BRICS, indicando proximidades e distâncias entre as economias analisadas e construindo um panorama global dessas regulamentações.

\section{A Teoria Institucional no Contexto Internacional}

Apresentada por Peng (2009) como um complemento às teorias baseadas em recursos e na indústria, a teoria institucional, cuja fundamentação se encontra nos trabalhos de North (1990) e Scott (1995), enumera aspectos formais e informais para compreender o fracasso ou sucesso de estratégias corporativas. Entre os aspectos formais que teriam um papel regulatório e coercitivo para as ações das companhias, podem ser apontados os regulamentos, leis e regras. Já como aspectos informais que teriam um caráter mais normativo e cognitivo, têm-se as normas, culturas e valores éticos.

Segundo Peng (2009), as instituições existem com o objetivo maior de reduzir as incertezas, influenciando as tomadas de decisão dos indivíduos e sinalizando quais seriam aceitas e quais não. Seus pressupostos básicos, então, relacionam-se com o fato dos administradores e empresas buscarem 
racionalmente seus interesses, fazendo escolhas estratégias dentro de restrições institucionais, bem como na combinação de instituições formais e informais que regem o comportamento das empresas, especialmente as últimas. A respeito das escolhas racionais, Peng, Sun, Pinkham e Chen (2009) declaram que, mesmo esta racionalidade sendo limitada e não perfeita, em termos de conveniência, obrigação social ou posição pessoal, tais escolhas podem carregar sua própria racionalidade. Quanto ao segundo pressuposto, de complementaridade entre instituições formais e informais, reconhece-se que, mediante relações contratuais, informais, baseadas em relacionamentos ou expectativas de trocas, as instituições acabam por influenciar nas escolhas estratégicas.

A partir da consideração desses elementos e buscando responder à questão acerca do que determina a estratégia e o desempenho das empresas em negócios internacionais, Peng, Wang e Jiang (2008) demonstram que esta estratégia não pode ser compreendida apenas a partir de uma visão baseada nos recursos de uma empresa ou na indústria a qual ela pertence. Dessa forma, a visão baseada nas instituições é ressaltada como a terceira perna de um tripé, como definem também Peng, Sun et al. (2009), sob o qual se sustentam as estratégias organizacionais, as quais, nesse contexto, são classificadas, por Peng (2009), como estratégia reativa, quando se nega uma responsabilidade, agindo passivamente a fim de fazer o menos esperado; estratégia defensiva, em que a responsabilidade é reconhecida, mas há uma resistência em fazer o mínimo esperado; estratégia adaptativa, há o reconhecimento da responsabilidade, bem como uma ação em vista do que se espera; e estratégia proativa, caracterizada pela ação máxima antecipada à responsabilidade.

Na defesa da importância da visão baseada em instituições para estratégias internacionais, Peng et al. (2008) concentram sua discussão no contexto das economias emergentes, apresentando algumas áreas sob as quais seu modelo teórico viria a contribuir, sendo elas: políticas antidumping como barreiras de entrada; competição dentro e fora da Índia; crescimento das empresas na China; e a governança das empresas nessas economias. A partir daí, os autores concluem que é inegável o crescente destaque do papel das instituições nas abordagens e estudos de estratégia internacional, tanto no contexto das economias emergentes quanto nas economias desenvolvidas, dessa maneira, complementando os aspectos destacados quanto à análise dos recursos organizacionais e indústrias. Sua maior contribuição, portanto, residiria na exploração de questões acerca do que direciona as estratégias internacionais das empresas e o que determina seu sucesso ou fracasso no ambiente competitivo internacional.

Contudo, apesar de contribuir para as discussões no campo da estratégia organizacional ao apresentar uma nova perspectiva para análise das ações das empresas e seus resultados alcançados, a visão baseada em instituições, como apresentada por Peng et al. (2008), acaba por incorrer nas mesmas limitações de suas antecessoras, a visão baseada em recursos e visão baseada na indústria. Por exemplo, as dificuldades da análise acerca de quais elementos foram determinantes no sucesso ou fracasso estratégico e de como mensurar esses impactos ainda permanece. Além disso, estudos que apresentem uma análise comparativa de elementos da teoria institucional em diferentes economias também são escassos.

Neste sentido, pode-se citar estudos recentes como o Matsnev (2006), que comparou elementos institucionais que influenciam o empreendedorismo na Rússia com outras economias, como os Estados Unidos; de Nasra e Dacin (2010), que investigou o papel do estado como empresário e empreendedor nos Emirados Árabes a partir dessa perspectiva institucional; e de Desa (2012), que analisou ambientes institucionais normativos desfavoráveis para o empreendedorismo no contexto internacional, utilizando dados de 45 países em seu trabalho. Assim, este trabalho se propõe a contribuir com as discussões já desenvolvidas no campo, desse modo, apresentando dados pertinentes às instituições formais, no caso, as regulamentações que afetam a realização de negócios em diferentes economias em todo o mundo, com destaque para os países que compõem o BRICS. 


\section{Realização de Negócios em Economias Emergentes: o Caso do BRICS}

Jim O’Neill (2001), presidente da Goldman Sachs Asset Management, foi o criador do acrônimo BRIC, utilizado em seus estudos sobre países emergentes, e que se refere a países que possuem grande potencial de crescimento e podem se tornar potências mundiais e, assim, superar economias como Estados Unidos, Japão, Alemanha, Reino Unido, França e Itália até o ano de 2050. A princípio, os países que compunham a sigla eram o Brasil, a Rússia, a Índia e a China. Apenas em 2011, a África do Sul passou a ser considerada como membro do BRICS, quando, em uma série de novos estudos, O’Neill (2011) observou a relevância de sua participação no mercado mundial.

Em economias emergentes, especialmente nestas que compõem o BRICS, as atividades de negócios se mostram como essenciais para o crescimento econômico e desenvolvimento de suas sociedades. Julien (2010) caracteriza os negócios nestas economias como dirigidos pela eficiência (efficiency-driven), pelo alto crescimento e desenvolvimento que esses países experimentaram nos últimos anos, através de incentivos públicos e fortalecimento do setor privado. Contudo o entendimento desse fenômeno nestas economias é ainda incipiente, pois, conforme Bruton et al. (2008), a utilização de teorias, como a teoria institucional (North, 1990; Scott, 1995), teoria baseada em recursos (Barney, 1991; Barney, Ketchen, \& Wright, 2011; Wernerfelt, 1984) ou a teoria dos custos de transação (Williamson, 1975, 1985, 1996, 2005, 2010), é quase sempre feita com pouco respeito ao contexto das economias emergentes. Deste modo, essas teorias seriam utilizadas para a compreensão da realização de negócios sem levar em consideração as diferenças existentes entre as economias emergentes e as economias desenvolvidas, onde essas teorias foram criadas.

Há, contudo, que se reconhecer o esforço de inúmeros pesquisadores que têm explorado aspectos particulares da realização de negócios em cada uma dessas economias. No caso do Brasil, Barros e Pereira (2008) destacam a importância crescente das pequenas empresas para a economia nacional. No entanto os autores ressalvam a presença forte dos negócios por necessidade no Brasil, visto que esta atividade poderia ser resultado de taxas altas de desemprego, sendo uma alternativa para essa escassez. Fenômeno semelhante ocorre na África do Sul, onde a realização de negócios também é motivada pelo fracasso dos setores público e privado em absorver toda a força de trabalho do país (Fatoki \& Patswawairi, 2012).

Em relação à Rússia, conforme McCarthy, Puffer e Shekshnia (1993), a realização de novos negócios é considerada um fenômeno recente, sendo anteriormente relacionada principalmente com atividades ilegais, tendo, dessa forma, uma conotação negativa. Volkov (1999), em complemento, confirma este aspecto ao abordar a relação entre o crime organizado e a criação de novos negócios, caracterizando o chamado empreendedorismo violento. Neste contexto, destacam-se estudos relativos à influência institucional nas atividades econômicas do país, principalmente aquelas relativas às mudanças geradas com o declínio do regime socialista, como os estudos de Berkowitz e DeJong (2005), que identificaram a importância do crescimento no nível educacional da população e de mudanças na orientação política como fatores de promoção da criação de novos negócios no país, e o estudo de Puffer, McCarthy e Boisot (2010), que investigou aspectos institucionais no país, como a confiança e os direitos de propriedade.

Considerada, segundo Khanka (2010), como o país asiático que mais opera iniciativas para o desenvolvimento de negócios, a Índia vive um impulso de crescimento fundamentado em inovações tecnológicas. Dessa forma, as pesquisas realizadas no contexto da Índia geralmente exploram o empreendedorismo em face do desenvolvimento de tecnologias, principalmente de tecnologias sustentáveis. Neste sentido, Raman (2010) caracteriza as ações da economia indiana como carentes de uma maior integração entre os setores público e privado. Tal limitação, contudo, não parece reduzir as taxas de crescimento de longo prazo da Índia, principalmente em um mercado voltado para serviços, como aponta Purushothaman (2004).

Diferindo da Índia por fundamentar suas atividades empreendedoras em uma economia de manufaturas, a China é uma economia caracterizada por imperfeições legais e institucionais, com 
mercados financeiros subdesenvolvidos e restrições de crédito (Yueh, 2012). Arbix (2009), no entanto, ressalva que se o país conseguir lidar com esses problemas de desigualdade social e democracia, poderá voltar ao lugar ocupado na Revolução Industrial. Deste modo, assim como na Rússia, são os aspectos institucionais os mais explorados pelos pesquisadores no campo, evidenciam Puffer et al. (2010).

Ademais, apesar do grande volume de produções relativo aos negócios desenvolvidos nestas economias emergentes, Bruton et al. (2008) apontam uma limitação no que diz respeito à desconsideração de aspectos de cunho internacional, como a internacionalização de novas empresas e o impacto das diferenças culturais neste processo de expansão. Assim, neste estudo, mesmo reconhecendo que o foco da análise se concentra nos países do BRICS, optou-se por analisar essas economias juntamente com todos os demais países, de forma a suprir esta lacuna apontada nas pesquisas do campo.

\section{Metodologia da Pesquisa}

Com o objetivo de caracterizar os países BRICS com base em uma análise de suas regulamentações que interferem na realização de negócios, o presente trabalho se classifica como uma pesquisa exploratória de cunho quantitativo. Essa escolha deve-se à sua relevância específica para o surgimento de descobertas em situações que não tem como objetivo testar hipóteses específicas (Hair, Babin, Money, \& Samouell, 2007). Além disso, segundo Cooper e Schindler (2003), a pesquisa exploratória tem sua utilidade "quando os pesquisadores não têm uma idéia clara dos problemas que vão enfrentar durante o estudo" (p. 131) ou quando a área de investigação é "tão vaga que o pesquisador precisa fazer uma exploração a fim de saber algo sobre o problema enfrentado" (p. 131). Dessa forma, tendo em vista a inexistência de estudos semelhantes, que avaliem as características das regulamentações relativas às atividades de negócios dos países BRICS em comparação com as demais economias globais, a utilização deste método de pesquisa se faz necessária.

No que diz respeito à escolha pela utilização de uma abordagem quantitativa, esta se justifica nas palavras de Minayo e Sanches (1993), que a indicam para "abarcar, do ponto de vista social, grandes aglomerados de dados, de conjuntos demográficos, por exemplo, classificando-os e tornando-os inteligíveis através de variáveis" (p. 247). Portanto, como esta pesquisa trabalha fundamentalmente com indicadores e variáveis dentro de um conjunto amplo de casos, sem ter a pretensão de explorar aspectos particulares de cada objeto, mas visando à construção de um panorama geral para o fenômeno analisado, entende-se que o método quantitativo é o mais indicado.

Como técnica exploratória, a análise de dados secundários foi utilizada. Segundo Malhotra (2006), algumas vantagens de sua utilização seriam o desenvolvimento de novas abordagens para um problema, possibilitando a identificação de variáveis-chave, mesmo tendo sido coletadas por um objetivo distinto daquele da pesquisa em questão. Nesta pesquisa, a coleta de dados secundários foi feita nos bancos de dados do Projeto Doing Business, realizado pelo Banco Mundial e Corporação Financeira Internacional. Lançado em 2002 e com o primeiro relatório publicado no ano de 2003, o Doing Business tem como objetivo examinar o desenvolvimento de pequenas e médias empresas nacionais a partir das regulamentações que influenciam suas atividades em todo o seu ciclo de vida. Para tanto, o projeto se utiliza de uma série de indicadores quantitativos para comparar os ambientes regulatórios de empresas em 185 países. A Tabela 1, a seguir, apresenta os indicadores de sua última versão, publicada em 2013. 
Tabela 1

Indicadores de Ambiente Regulatório do Doing Business

\begin{tabular}{|c|c|}
\hline Indicadores & Descrição \\
\hline Abertura de empresas & $\begin{array}{l}\text { Procedimentos necessários, ou comuns na prática, para a abertura e } \\
\text { operação formal de uma empresa. }\end{array}$ \\
\hline Obtenção de alvarás de construção & $\begin{array}{l}\text { Procedimentos necessários para uma empresa do setor de construção } \\
\text { construir um depósito. }\end{array}$ \\
\hline Obtenção de eletricidade & $\begin{array}{l}\text { Procedimentos necessários para uma empresa obter conexão e } \\
\text { fornecimento permanente de eletricidade. }\end{array}$ \\
\hline Registro de propriedades & $\begin{array}{l}\text { Procedimentos necessários para uma empresa (comprador) adquirir } \\
\text { uma propriedade de outra empresa (vendedor) e transferir o título de } \\
\text { propriedade para o nome do comprador. }\end{array}$ \\
\hline Obtenção de crédito & $\begin{array}{l}\text { Direitos legais dos mutuários e mutuantes no tocante às transações } \\
\text { garantidas e à troca de informações sobre crédito. }\end{array}$ \\
\hline Proteção de investidores & $\begin{array}{l}\text { Solidez das proteções aos acionistas minoritários contra o uso } \\
\text { inadequado dos bens sociais, por parte dos diretores, para ganhos } \\
\text { pessoais. }\end{array}$ \\
\hline Pagamento de impostos & $\begin{array}{l}\text { Número total de impostos e contribuições pagos, o método de } \\
\text { pagamento, a frequência de pagamento, a frequência de declaração e o } \\
\text { número de organismos envolvidos durante o segundo ano de operação. }\end{array}$ \\
\hline Comércio entre fronteiras & $\begin{array}{l}\text { Requisitos e procedimentos para exportação e importação de uma } \\
\text { carga padronizada de mercadorias por transporte marítimo. }\end{array}$ \\
\hline Execução de contratos & $\begin{array}{l}\text { Eficiência do sistema judicial para solucionar controvérsias } \\
\text { comerciais. }\end{array}$ \\
\hline Resolução de insolvência & $\begin{array}{l}\text { Tempo, custo e resultados dos procedimentos de insolvência que } \\
\text { envolvem as entidades nacionais. }\end{array}$ \\
\hline
\end{tabular}

Nota. Fonte: Adaptado de World Bank. (2013). Doing Business 2013: smarter regulations for small and medium-size enterprises (p. 13). Washington, DC: Author. doi: 10.1596/978-0-8213-9615-5

Para este estudo, foi utilizada a pesquisa mais recente disponível no banco de dados, referente ao ano de 2013, que apresenta dados de 185 economias para cada um desses indicadores. Tal amostra se caracteriza como estratificada desproporcional, caso em que sua alocação se determina "pelo julgamento, com base na idéia de que cada estrato é grande o suficiente para assegurar níveis de confiança adequados e estimativas de amplitude de intervalos para estratos individuais" (Cooper \& Schindler, 2003, p. 165). A análise de tais dados se deu em uma situação de estudo transversal em que "os dados são coletados em um único ponto no tempo e sintetizados estatisticamente” (Hair et al., 2007, p. 87).

Para a análise exploratória dos dados, foi utilizada a técnica estatística de análise de conglomerados, definida, por Pohlmann (2009, p. 325), como "uma das técnicas de análise multivariada cujo propósito primário é reunir objetos, baseando-se nas características dos mesmos". Desse modo, tendo em vista possibilitar uma análise comparativa dos países BRICS com as demais economias existentes no mundo, a contribuição da aplicação da técnica de conglomerados estaria em reduzir o grande volume de casos, referentes aos 185 países considerados na análise, em uma quantidade menor de grupos que permitisse essa apreciação. Como softwares de auxílio à pesquisa foram utilizados o Microsoft Excel (versão 2012) e o IBM SPSS (versão 21), tendo em vista a organização dos dados e a construção de tabelas e gráficos como suporte à análise. 


\section{Apresentação e Análise dos Resultados}

A fim de possibilitar uma descrição taxonômica das economias analisadas, com base nas informações constantes no relatório de 2013 do Doing Business, iniciou-se a análise estatística com a verificação dos pressupostos que atendem e validam a utilização da técnica de análise de conglomerados. Primeiramente, em relação à representatividade da amostra, neste estudo, optou-se pela utilização do conjunto total de países que se inserem na pesquisa do Doing Business, sendo este número, atualmente, de 185 países, representando quase que a totalidade de países existentes no mundo. Dessa forma, podese inferir que a amostra utilizada nesta pesquisa é representativa da população.

Em seguida, outro pressuposto considerado para a validação da aplicação da análise de conglomerados diz respeito à ausência de multicolinearidade entre as variáveis selecionadas, de forma que não existam variáveis altamente correlacionadas entre si. Para verificar a observância desse pressuposto, realizou-se análise de correlação entre todas as variáveis, cujos coeficientes são apresentados na Tabela 2, a seguir.

Tabela 2

Matriz de Correlações Entre as Variáveis (Coeficiente de Pearson)

\begin{tabular}{|c|c|c|c|c|c|c|c|c|c|c|}
\hline & 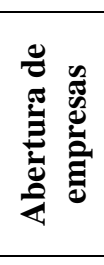 & 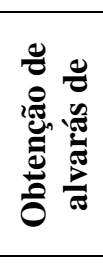 & 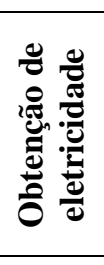 & 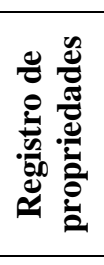 & 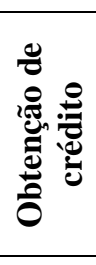 & 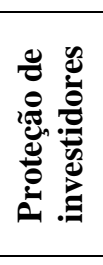 & 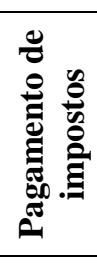 & 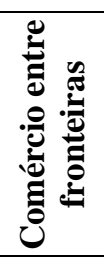 & 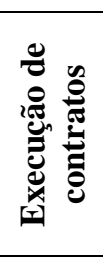 & 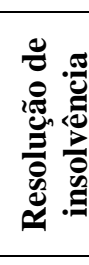 \\
\hline bertura de en & 1 &, 341 & ,276 & ,302 & ,439 & ,602 & ,397 & ,402 & ,400 & ,434 \\
\hline Obtenção de alvarás de construção &, 341 & 1 & ,485 &, 241 &, 187 & ,213 &, 412 & ,490 &, 232 &, 357 \\
\hline Obtenção de eletricidade &, 276 & ,485 & 1 &, 257 &, 222 &, 219 & ,461 &, 580 &, 239 &, 323 \\
\hline Registro de propriedades & ,302 &, 241 &, 257 & 1 &, 375 & ,329 &, 373 &, 290 &, 502 & ,375 \\
\hline Obter & ,439 &, 187 &, 222 &, 375 & 1 & ,488 &, 258 & ,382 & ,425 & ,489 \\
\hline Proteção de investidore & ,602 &, 213 & ,219 &, 329 & ,488 & 1 & ,394 & ,364 & ,297 & ,408 \\
\hline Pagamento de impostos &, 397 &, 412 & ,461 &, 373 &, 258 & ,394 & 1 & ,497 &, 328 &, 420 \\
\hline Comércio entre fronteiras & ,402 & ,490 &, 580 &, 290 &, 382 & ,364 & ,497 & 1 & ,356 &, 545 \\
\hline Execução de c &, 400 &, 232 & ,239 &, 502 &, 425 &, 297 &, 328 &, 356 & 1 &, 460 \\
\hline Resolução de insolvência & ,434 &, 357 & ,323 & ,375 & ,489 & ,408 & ,420 &, 545 & ,460 & 1 \\
\hline
\end{tabular}

Nota. Fonte: Dados da pesquisa.

A partir da análise dessa matriz de coeficientes de correlações de Pearson entre as variáveis, podese constatar que não existem variáveis com alto grau de correlação entre si (coeficiente $p>0,7$ ). Dessa forma, todas as 10 variáveis puderam ser mantidas para aplicação da técnica de conglomerados.

Com relação ao tipo de algoritmo de agrupamento, optou-se pela utilização do método não hierárquico de agrupamento K-médias (K-means), comumente usado para o agrupamento de grandes conjuntos de casos ou observações, como é o caso deste estudo em particular. Os resultados desta primeira solução, com agrupamento dos países em quatro grupos, são apresentados na Tabela 3, a seguir, com destaque para a alocação dos países BRICS. 
Tabela 3

\section{Classificação dos Países nos Grupos}

\begin{tabular}{|c|c|c|c|}
\hline \multirow{2}{*}{$\begin{array}{l}\text { GRUPO } 1 \text { - } 43 \text { Países } \\
\text {. África do Sul }\end{array}$} & \multicolumn{3}{|c|}{ GRUPO 2 - 43 Países } \\
\hline & Marrocos & . Albânia & . Moçambique \\
\hline . Antígua e Barbuda & México & Argentina & Moldova \\
\hline Bahamas & Montenegro & . Azerbaijão & . Mongólia \\
\hline Barbados & Namíbia & Bangladesh & . Nepal \\
\hline Belize & . Panamá & Bielorrússia & . Nicarágua \\
\hline . Brunei Darussalam & . Papua-Nova Guiné & Bósnia e Herzegovina & Nigéria \\
\hline . Colômbia & Paraguai & Botsuana & . Paquistão \\
\hline . Croácia & Peru & Bulgária & . Polônia \\
\hline Dominica & $\begin{array}{l}\text { Porto Rico (Estados } \\
\text { Unidos) }\end{array}$ & . Burundi & . Quirguistão \\
\hline . Fiji & . Ruanda & Butão & . República Checa \\
\hline Grécia & Samoa Ocidental & . Cazaquistão & . Romênia \\
\hline Granada & Santa Lúcia & $\begin{array}{l}\text { China, República } \\
\text { Popular da }\end{array}$ & . Rússia, Federação da \\
\hline . Ilhas Marshall & São Cristóvão e Neves & Egito & Serra Leoa \\
\hline . Ilhas Salomão & $\begin{array}{l}\text { São Vicente e } \\
\text { Granadinas }\end{array}$ & El Salvador & Sérvia \\
\hline . Israel & Seicheles, República das & Gana & . Tadjiquistão \\
\hline . Itália & Sri Lanka & Índia & . Tanzânia \\
\hline Jamaica & Tonga & $\begin{array}{l}\text { Irã, República Islâmica } \\
\text { do }\end{array}$ & . Turquia \\
\hline Jordânia & Trindade e Tobago & Kiribati & . Ucrânia \\
\hline Kuwait & Uruguai & Kosovo & . Uganda \\
\hline . Líbano & Vanuatu & Madagascar & . Uzbequistão \\
\hline . Luxemburgo & & . Maláui & . Vietnã \\
\hline Maldivas & & & . Zâmbia \\
\hline \multicolumn{4}{|l|}{ Malta } \\
\hline GRUPO 3 - 55 Países & & GRUPO 4 - 44 Países & \\
\hline Afeganistão & Guiné-Bissau & Alemanha & . Geórgia \\
\hline . Angola & . Haiti & . Arábia Saudita & . Hong Kong RAE, China \\
\hline . Argélia & . Honduras & Armênia & . Hungria \\
\hline Benin & . Iêmen, República do & . Austrália & . Ilhas Maurício \\
\hline . Bolívia & Indonésia & . Áustria & . Irlanda \\
\hline Brasil & Iraque & . Barém & . Islândia \\
\hline Burkina Faso & $\begin{array}{l}\text { Laos, República } \\
\text { Democrática Popular do }\end{array}$ & . Bélgica & . Japão \\
\hline
\end{tabular}




\section{Tabela 3 (continuação)}

\begin{tabular}{llll}
\hline GRUPO 3-55 Países & & GRUPO 4-44 Países & \\
\hline . Cabo Verde & . Lesoto & . Canadá & . Letônia \\
. Camarões & . Libéria & . Catar & . Lituânia \\
. Camboja & . Mali, República do & . Chile & . Macedônia, Antiga \\
& República Iugoslava da \\
. Chade & . Mauritânia & . Chipre & . Malásia \\
. Cisjordânia e Faixa de & . Micronésia, Estados & . Cingapura & . Noruega \\
Gaza & Federados da & & \\
. Comores & . Níger & . Coreia, República da & . Nova Zelândia \\
. Congo, República & . Palau & . Dinamarca & . Omã \\
Democrática do & . Quênia & . Emirados Árabes Unidos & . Países Baixos \\
. Congo, República do & . República Centro- & . Eslováquia & . Portugal \\
. Costa do Marfim & Africana & . Eslovênia & . Reino Unido \\
Costa Rica & . República Dominicana & . & . Suécia \\
. Djibuti & . São Tomé e Príncipe & . Espanha & . Suíça \\
. Equador & . Senegal & . Estados Unidos da & América \\
. Eritreia & . Síria & . Estônia & . Tailândia \\
. Etiópia & . Suazilândia & . Finlândia & . Taiwan, China \\
. Filipinas & . Sudão & . França & . Tunísia \\
. Gabão & . Suriname & & \\
. Gâmbia & . Timor Leste & & \\
. Guatemala & . Togo & & \\
Guiana, RC & Guiné & & \\
. Guiné Equatiana da & & \\
\hline
\end{tabular}

Nota. Fonte: Dados da pesquisa.

Para validar a construção dos grupos apresentados a partir da análise das variáveis que influenciaram sua organização, realizou-se análise de variância (ANOVA) nas variáveis utilizadas. Ressalta-se que o intuito com a sua utilização não consistiu em verificar se os grupos são ou não diferentes, mas em identificar quais variáveis permitiram a separação dos grupos e quais variáveis não foram significativas neste processo de separação. Essa identificação é feita a partir dos valores de sig., que devem ser menores que 0,05. Além disso, a utilização da ANOVA permite classificar as variáveis pela sua importância no processo de separação. Assim, as variáveis que mais apresentaram valor estatístico de F seriam as que mais influenciaram na separação dos grupos. A Tabela 4, que segue, apresenta os resultados desta análise. 
Tabela 4

Análise de Variância ANOVA

\begin{tabular}{lcccccc}
\cline { 2 - 5 } & \multicolumn{2}{c}{ Cluster } & \multicolumn{2}{c}{ Erro } & F & \multirow{2}{*}{ Sig. } \\
\cline { 2 - 5 } & $\begin{array}{c}\text { Quadrado } \\
\text { Médio }\end{array}$ & df & $\begin{array}{c}\text { Quadrado } \\
\text { Médio }\end{array}$ & df & & \\
\hline Abertura de empresas & 80631,237 & 3 & 1578,734 & 181 & 51,073 &, 000 \\
Obtenção de alvarás de construção & 77533,120 & 3 & 1632,755 & 181 & 47,486 &, 000 \\
Obtenção de eletricidade & 85434,222 & 3 & 1501,292 & 181 & 56,907 &, 000 \\
Registro de propriedades & 60057,587 & 3 & 1921,655 & 181 & 31,253 &, 000 \\
Obtenção de crédito & 60611,928 & 3 & 1858,059 & 181 & 32,621 &, 000 \\
Proteção de investidores & 76479,342 & 3 & 1670,421 & 181 & 45,784 &, 000 \\
Pagamento de impostos & 71583,358 & 3 & 1725,174 & 181 & 41,493 &, 000 \\
Comércio entre fronteiras & 94774,997 & 3 & 1344,010 & 181 & 70,517 &, 000 \\
Execução de contratos & 67734,608 & 3 & 1788,753 & 181 & 37,867 &, 000 \\
Resolução de Insolvência & 92063,647 & 3 & 1503,819 & 181 & 61,220 &, 000 \\
\hline
\end{tabular}

Nota. Os testes F devem ser usados apenas para finalidades descritivas porque os clusters foram escolhidos para maximizar as diferenças entre os casos em clusters diferentes. Os níveis de significância observados não estão corrigidos para isso e, dessa forma, não podem ser interpretados como testes da hipótese de que as médias de cluster são iguais. Fonte: Dados da pesquisa.

Como pode ser observado, todas as variáveis utilizadas apresentaram um coeficiente de significância menor que 0,05 (sig. = 0,000). Dessa forma, considera-se que todas as 10 variáveis utilizadas na aplicação da técnica de conglomerados revelaram-se significantes para a formação dos quatro grupos, com nível de significância de $5 \%$. A variável Comércio entre fronteiras $(\mathrm{F}=70,517)$ foi a que mais discriminou os países de cada grupo, seguida das variáveis Resolução da insolvência $(\mathrm{F}=$ 61,220), Obtenção de eletricidade $(F=56,907)$ e Abertura de empresas $(F=51,073)$. Em contrapartida, as variáveis que menos influenciaram a separação dos grupos foram Registro de propriedades $(\mathrm{F}=$ $31,253)$ e Obtenção de crédito $(\mathrm{F}=32,621)$.

Em consequência a verificar as diferenças entre os grupos em cada uma das variáveis, foram utilizados valores da distância média das observações em relação ao centro do grupo após a formação dos diferentes conglomerados, apresentados na Tabela 5, a seguir.

Tabela 5

Centros de Conglomerados Finais

\begin{tabular}{lcccc}
\cline { 2 - 5 } & \multicolumn{4}{c}{ Cluster } \\
\cline { 2 - 5 } & $\mathbf{1}$ & $\mathbf{2}$ & $\mathbf{3}$ & $\mathbf{4}$ \\
\hline Abertura de empresas & 76 & 91 & 144 & 49 \\
Obtenção de alvarás de construção & 73 & 140 & 110 & 44 \\
Obtenção de eletricidade & 68 & 141 & 114 & 44 \\
Registro de propriedades & 117 & 85 & 120 & 43 \\
Obtenção de crédito & 86 & 73 & 128 & 44 \\
\hline
\end{tabular}


Tabela 5 (continuação)

\begin{tabular}{lcccc} 
& \multicolumn{4}{c}{ Cluster } \\
\cline { 2 - 5 } & $\mathbf{1}$ & $\mathbf{2}$ & $\mathbf{3}$ & $\mathbf{4}$ \\
\hline Proteção de investidores & 68 & 77 & 140 & 51 \\
Pagamento de impostos & 79 & 112 & 130 & 42 \\
Comércio entre fronteiras & 80 & 126 & 127 & 31 \\
Execução de contratos & 107 & 81 & 131 & 43 \\
Resolução de Insolvência & 84 & 105 & 139 & 35 \\
\hline
\end{tabular}

Nota. Fonte: Dados da pesquisa.

Entre os grupos apresentados na análise, o Grupo 4 se destaca dos demais como aquele com os menores valores em todas as variáveis, sendo, portanto, o grupo cujos países teriam as características mais favoráveis para a criação e desenvolvimento de novos empreendimentos. Esse grupo é formado, em sua maioria, por países de economia desenvolvida, como Finlândia, Reino Unido e Suíça, além das consideradas potências mundiais apontadas por O'Neill (2001), como Alemanha, Estados Unidos e Japão. Assim, nenhum dos países BRICS foi alocado neste grupo.

A respeito de algumas características deste que seria o grupo com os melhores países para a criação de novos negócios, levando-se em consideração os aspectos institucionais relativos às variáveis consideradas, pode-se destacar a duração média de somente 10 dias para o processo de abertura de empresas e o baixíssimo nível de custos nesse processo de abertura (3,56\%). Ademais, o número médio de dias para o registro de propriedades também foi significativamente inferior ao dos outros grupos $(20,7$ dias), assim como o número médio de impostos a serem pagos (10,77 impostos) e o tempo de trabalho para pagamento desses impostos $(158,20$ horas/ano). Por fim, em relação à variável comércio entre fronteiras, esse grupo apresentou os aspectos institucionais mais favoráveis para a realização de transações internacionais, com menor número de documentos exigidos, tempo e custos.

A representação gráfica dos valores médios de cada variável se encontra na Figura 1, que segue, onde foi incluída a variável facilidade em fazer negócios, que consiste em um indicador geral que reúne as outras 10 variáveis utilizadas.

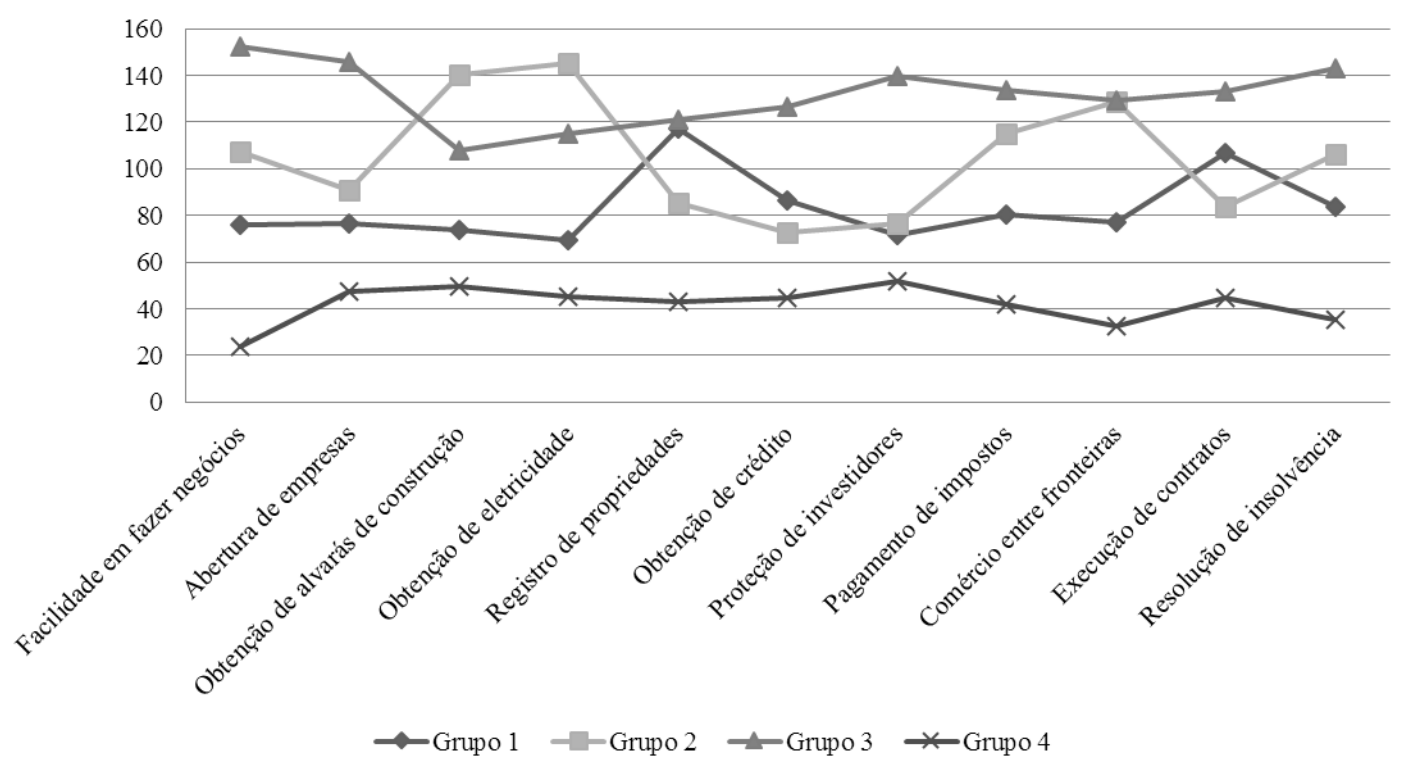

Figura 1. Distribuição Média das Variáveis em Cada Grupo Fonte: Dados da pesquisa. 
Em relação aos demais grupos, o indicador geral de facilidade em fazer negócios apontou o Grupo 1, da África do Sul, como o segundo melhor grupo de países para a criação de novos empreendimentos, seguido do Grupo 2, da China, Índia e Rússia, e Grupo 3, do Brasil; este último, portanto, formado pelos países com regulamentações menos favoráveis para a prática de empreendedorismo. As características econômicas da África do Sul são discutidas, por Mahadea (2012), em termos de ação empresarial e aspectos institucionais. Assim, apesar de ter se destacado em relação aos demais países nesta análise, que tem como foco aspectos regulatórios, sua atividade empreendedora ainda é das mais baixas entre esses países, principalmente devido a elementos como corrupção, governança e baixa educação (Herrington, 2011). Assim, é preciso aprofundar a análise, indo além desse índice geral, para tanto, explorando os resultados das demais variáveis do estudo dentro de cada um dos grupos.

Para a variável abertura de empresas, o Grupo 1, da África do Sul, é formado por países com melhores características entre os três grupos. Apesar de ter um tempo médio para abertura de empresas um pouco superior ao dos países do Grupo 2 (22,51 dias e 22,17 dias, respectivamente), esse grupo se destaca na quantidade menor de procedimentos, custos e capital a ser integralizado. Já os países do Grupo 3, que apresentaram piores características para a abertura de empresas, têm como duração média para este processo 57,78 dias, mais que o dobro dos outros dois grupos, tendo, também, os maiores níveis de custos de abertura. Como integrante deste último grupo, o Brasil tem sido comumente destacado em relação à sua excessiva burocracia, como apontam Pedroso, Massukado-Nakatani e Mussi (2009), o que pode afetar diretamente os custos e prazo para a abertura de empresas.

No entanto, para as variáveis de obtenção de alvarás de construção e obtenção de eletricidade, foi o Grupo 2 que apresentou as piores médias para os indicadores. Para este grupo de países, em que se inserem a China, Índia e Rússia, o número médio de procedimentos, em ambos os casos, revelou-se superior aos dos demais grupos (20,94 para a obtenção de alvarás e 6,61 para obtenção de eletricidade). Além disso, possivelmente por questões geográficas, a duração do processo de obtenção de eletricidade é muito superior a dos Grupos 1 e 3, sendo de 153,74 dias para o primeiro, e 78,80 e 109,74 dias para os últimos, respectivamente.

De fato, o setor energético chinês tem sido alvo de inúmeras discussões (Bleveans, 2000; Guy \& Liang, 2012; Pittman \& Zhang, 2010; Tseng, 2011; Yeh \& Lewis, 2004), sendo apontados como problemas principais: a falta de incentivos para as empresas fornecedoras, preocupações geopolíticas sobre a segurança energética, problemas com as empresas estatais, distorções de preço e manipulações de mercado. Quanto à Rússia, destacam-se os movimentos de barganhas políticas na estruturação do setor elétrico (Wengle, 2012). Já no caso da Índia, as restrições recaem sobre a falta de incentivos à eficiência do setor, influência governamental negativa e problemas técnicos, como a idade dos equipamentos e qualidade dos materiais utilizados na produção de energia, o que leva a altas tarifas e problemas de fornecimento (Kale, 2004; Khanna \& Zilberman, 1999; Ninan, 2012).

Em relação à variável registro de propriedades, não foram percebidas diferenças significativas entre os Grupos 1 e 3, ficando o Grupo 2 com os melhores valores indicativos em todos os aspectos (número de procedimentos: 6,39; duração: 56,60 dias; custo sobre o valor do imóvel: 4,28\%). Também, para a obtenção de crédito, o Grupo 2 apresentou os melhores indicativos, ficando o Grupo 3, do Brasil, em último lugar, com piores índices de eficiência dos direitos legais $(4,50)$ e de alcance das informações de crédito $(2,15)$. Como razões para esse resultado, pode-se ressaltar o discutido por Fachada, Figueiredo e Lundberg (2003), que caracterizam o mercado de crédito brasileiro como dotado de oferta reprimida e custo elevado, sendo ainda mitigado por uma morosidade judicial que dificulta o recebimento de valores contratados. Assim, como afirmado por Barone e Sader (2008, p. 1263), "muito ainda precisa ser feito em termos de crédito produtivo orientado, microcrédito, crédito para o consumo e bancarização no Brasil".

Para a variável proteção de investidores, o Grupo 1 apresentou os melhores aspectos regulatórios, levando-se em consideração os índices de responsabilidade dos diretores $(5,77)$, facilidade de processosacionistas $(6,67)$ e de eficiência da proteção ao investidor $(5,76)$, seguido do Grupo 2, que possui características bastante semelhantes nestes mesmos índices, mas que superou o Grupo 1 no índice de transparência (6,14 para o Grupo 2 e 4,87 para o Grupo 1). Quanto ao Grupo 3, este apresentou os piores 
indicativos em todos os índices relativos à variável proteção aos investidores, comportamento que se repete também em relação às variáveis pagamento de impostos e resolução de insolvência. Ao reconhecer os inúmeros efeitos da tributação para economias e empresas, no caso do Brasil, apesar dessa ser uma política que visa ao crescimento econômico, percebeu-se que a carga tributária lançada sobre os novos empreendimentos acaba por desestimular o seu desenvolvimento, como discutido por Cohn, Rainwater e Bradshaw (2004). Ao contrário, as políticas de tributação da África do Sul têm ido em direção a uma redução significativa desses impostos (Pama, 2004).

No tocante à variável comércio entre fronteiras, os Grupos 2 e 3 apresentaram médias semelhantes, estando o Grupo 1 com aspectos mais favorecedores às relações comerciais internacionais, principalmente à exportação, em todos os índices analisados, sendo eles: documentos para exportar: 5,91; tempo para exportar: 16,98 dias; custo para exportar: US $\$ 1.155,08$ por contêiner; documentos para importar: 6,87 número; tempo para importar: 17,94 dias; custo para importar: US $\$ 1.469,47$ por contêiner. Neste contexto, a África do Sul ganha destaque no comércio internacional entre os próprios países do BRICS, crescendo entre os anos de 1992 e 2008 acima da média mundial (Pautasso, 2010).

Por fim, para a variável execução de contratos, são os países do Grupo 2 que revelaram melhores médias, superando os países do Grupo 1 e do Grupo 3 em todos os aspectos, tanto na duração do processo $(565,35$ dias) e no número de procedimentos $(36,99)$ quanto em relação ao custo destas execuções de contrato $(33,16 \%$ da dívida).

De forma geral, pôde-se observar o posicionamento de cada grupo em relação aos demais, identificando quais seriam os pares de grupos mais próximos ao serem consideradas todas as variáveis utilizadas na análise. A Tabela 6, a seguir, apresenta essas distâncias entre os grupos.

Tabela 6

Distâncias entre Centros de Conglomerados Finais

\begin{tabular}{ccccc}
\hline Cluster & $\mathbf{1}$ & $\mathbf{2}$ & $\mathbf{3}$ & $\mathbf{4}$ \\
\hline $\mathbf{1}$ & & 125,241 & 153,091 & 141,750 \\
$\mathbf{2}$ & 125,241 & & 128,700 & 209,636 \\
$\mathbf{3}$ & 153,091 & 128,700 & & 273,381 \\
$\mathbf{4}$ & 141,750 & 209,636 & 273,381 & \\
\hline
\end{tabular}

Nota. Fonte: Dados da pesquisa.

Desse modo, é possível inferir que o grupo mais próximo ao Grupo 4, que foi o que apresentou os melhores aspectos regulatórios em todas as variáveis consideradas no estudo, é o Grupo 1, da África do Sul. Em relação aos outros dois grupos, o Grupo 2, que tem como países integrantes China, Índia e Rússia, seria o mais próximo do Grupo 1, permanecendo os países do Grupo 3, onde foi alocado o Brasil, em um posicionamento mais distante dos demais grupos, corroborando a discussão apresentada anteriormente.

\section{Considerações Finais}

Ao reconhecer a importância da criação de novos negócios para o desenvolvimento das economias, principalmente em um contexto internacional, o aprimoramento de políticas públicas que incentivem o crescimento da realização de negócios, tanto em países emergentes como naqueles não desenvolvidos economicamente, mostra-se urgente. Nesta pesquisa, que teve como objetivo caracterizar os países BRICS com base em uma análise das regulamentações que interferem na realização de negócios, foi possível observar, a partir dos grupos criados pela análise estatística de conglomerados, os 
diferentes níveis de desenvolvimento em que se encontram esses elementos regulatórios no mundo. Ao agrupar as economias em grupos semelhantes quanto ao ambiente institucional de regulamentações de negócios, foi possível perceber pontos-chave de melhoria em determinados grupos de países. A Tabela 7, a seguir, apresenta um resumo das características encontradas em cada um dos grupos de países analisados.

Tabela 7

\section{Perfil dos Grupos}

\begin{tabular}{|c|c|}
\hline GRUPOS & CARACTERÍSTICAS \\
\hline $\begin{array}{l}\text { Grupo } 1 \\
\text { (África do Sul) }\end{array}$ & $\begin{array}{l}\text { Segundo melhor grupo de países em facilidade para fazer negócios. Ambiente favorável à } \\
\text { abertura de empresas, obtenção de alvarás e de eletricidade, proteção de investidores, } \\
\text { pagamento de impostos, comércio entre fronteiras e resolução de insolvência. }\end{array}$ \\
\hline $\begin{array}{l}\text { Grupo } 2 \\
\text { (China, Índia e } \\
\text { Rússia) }\end{array}$ & $\begin{array}{l}\text { Terceiro melhor grupo de países em facilidade para fazer negócios. Ambiente regulatório } \\
\text { com características favoráveis ao registro de propriedade e obtenção de crédito e execução } \\
\text { de contratos. }\end{array}$ \\
\hline $\begin{array}{l}\text { Grupo } 3 \\
\text { (Brasil) }\end{array}$ & $\begin{array}{l}\text { Grupo de países com piores indicadores relativos à facilidade para fazer negócios, } \\
\text { principalmente nos processos de abertura de empresas, obtenção de crédito, proteção de } \\
\text { investidores, pagamento de impostos, execução de contratos e resolução de insolvência. }\end{array}$ \\
\hline $\begin{array}{l}\text { Grupo } 4 \\
\text { (Sem membros do } \\
\text { BRICS) }\end{array}$ & $\begin{array}{l}\text { Grupo com os melhores países em facilidade para fazer negócios. Formado em sua grande } \\
\text { maioria por economias desenvolvidas e com aspectos regulatórios favoráveis em todos os } \\
\text { indicadores, com destaque para o de comércio entre fronteiras. }\end{array}$ \\
\hline
\end{tabular}

Nota. Fonte: Elaborado pelos autores.

Os achados deste estudo apresentam implicações em diversos contextos. Para a esfera pública, a caracterização realizada nos quatro grupos de países permite a construção de um quadro geral para melhorias regulatórias em cada uma das economias analisadas. Neste sentido, é possível perceber, a partir dos dados expostos, quais os principais entraves regulatórios no processo de criação e desenvolvimento de novos negócios. Assim, pode-se apontar, por exemplo, uma necessidade urgente para os países do Grupo 3, onde foi alocado o Brasil, em melhorias quanto à burocracia exigida para a abertura de empresas, além de uma melhor promoção das reservas de crédito para novos empreendimentos, a exemplo da África do Sul, que foi o país melhor avaliado neste aspecto. Da mesma forma, para os países do Grupo 2, especialmente China, Índia e Rússia, evidenciam-se limitações atinentes aos seus regulamentos no âmbito das atividades de importação e de exportação. Já para os países do Grupo 1, da África do Sul, também, pode-se apontar como pontos fracos os regulamentos relativos às atividades de comércio exterior, pagamento de impostos e registro de propriedades. Até mesmo para os países do Grupo 4, melhor avaliados em todas as variáveis consideradas, é possível assinalar a necessidade de melhorias nos processos de abertura de empresas e proteção aos investidores, pois estas foram as variáveis em que esses países obtiveram pior avaliação.

Em complemento, no contexto do setor privado, este estudo também se apresenta com implicações interessantes, especialmente para organizações que desejam atuar internacionalmente, investindo ou criando negócios em outras economias. Países que tenham, por exemplo, aspectos regulatórios problemáticos nas atividades de comércio exterior, como a Rússia, poderiam indicar possibilidades pouco viáveis neste sentido. Já para gestores com baixa propensão ao risco e que, dessa forma, valorizassem políticas de proteção aos investidores, a África do Sul poderia se mostrar como uma opção interessante de investimento.

Há, contudo, de se ressaltar que os grupos formados a partir da análise estatística empregada fornecem um quadro comparativo que leva em consideração todas as 185 economias utilizadas na pesquisa, constituindo-se, assim, como um panorama geral das regulamentações relativas às atividades de negócios. No entanto, por se tratar de uma técnica descritiva, a análise de conglomerados não traz 
respostas conclusivas acerca do fenômeno estudado, demandando estudos posteriores que investiguem as características destacadas por meio da aplicação desta análise. Além disso, sendo a composição dos grupos totalmente influenciada pelas variáveis, reconhece-se que a solução obtida é exclusiva para o conjunto utilizado de variáveis.

Dessa forma, este estudo não elimina a necessidade constante de pesquisas como as tradicionalmente realizadas, que exploram em profundidade as particularidades de cada um desses países, sem, contudo, desprezar o contexto internacional no qual eles se inserem. Além disso, a realização de estudos longitudinais, que busquem investigar mudanças no comportamento dos países BRICS em relação aos outros países, ao longo da última década, período de existência do projeto Doing Business, viriam também a contribuir com os resultados aqui apresentados, dessa maneira, evidenciando prováveis evoluções ou até mesmo regressões referentes ao ambiente regulatório desses países.

\section{Referências}

Arbix, G. (2009). BRICS, the Chinese engine, and the humbling of market fundamentalism. In J. Moscardo \& C. H. Cardim (Orgs.), Conferência nacional de política externa e política internacional (pp. 245-261). Brasília: Fundação Alexandre de Gusmão - Ministério das Relações Exteriores.

Barney, J. (1991). Firm resources and sustained competitive advantage. Journal of Management, 17(1), 99-120. doi: 10.1177/014920639101700108

Barney, J. B., Ketchen, D. J., \& Wright, M. (2011). The future of resource-based theory: revitalization or decline?. Journal of Management, 37(5), 1299-1315. doi: 10.1177/0149206310391805

Barone, F. M., \& Sader, E. (2008). Acesso ao crédito no Brasil: evolução e perspectivas. Revista de Administração Pública, 42(6), 1249-1267. doi: 10.1590/S0034-76122008000600012

Barros, A. A. de, \& Pereira, C. M. M. A. de (2008). Empreendedorismo e crescimento econômico: uma análise empírica. Revista de Administração Contemporânea, 12(4), 975-993. doi: 10.1590/S141565552008000400005

Berkowitz, D., \& DeJong, D. N. (2005). Entrepreneurship and post-socialist growth. Oxford Bulletin of Economics and Statistics, 67(1), 25-46. doi: 10.1111/j.1468-0084.2005.00108.x

Bleveans, L. E. (2000). Easing the transition to a competitive electricity market in China: a role for tolling agreements. Journal of Project Finance, 5(4), 33-39. doi: 10.3905/jsf.2000.32020

Bruton, G. D., Ahlstrom, D., \& Obloj, K. (2008). Entrepreneurship in emerging economies: where are we today and where should the research go in the future. Entrepreneurship Theory and Practice, 32(1), 1-14. doi: 10.1111/j.1540-6520.2007.00213.x

Cohn, S., Rainwater, E., \& Bradshaw, M. (2004). Do taxes lower employment in the third world? Evidence from personal service firms in pre-debt-crisis Brazil. Competition \& Change, 8(1), 4564. doi:10.1080/1024529042000269789

Cooper, D. R., \& Schindler, P. S. (2003). Métodos de pesquisa em administração (7a ed.). Porto Alegre: Bookman.

Coviello, N. E., McDougall, P. P., \& Oviatt, B. M. (2011). The emergence, advance and future of international entrepreneurship research - An introduction to the special forum. Journal of Business Venturing, 26(6), 625-631. doi: 10.1016/j.jbusvent.2011.07.002 
Desa, G. (2012). Resource mobilization in international social entrepreneurship: bricolage as a mechanism of institutional transformation. Entrepreneurship: Theory \& Practice, 36(4), 727-751. doi: $10.1111 /$ j.1540-6520.2010.00430.x

Fachada, P., Figueiredo, L. F., \& Lundberg, E. (2003). Sistema judicial e mercado de crédito no Brasil. Notas Técnicas do Banco Central do Brasil, 35, 1-21.

Fatoki, O., \& Patswawairi, T. (2012). The motivations and obstacles to immigrant entrepreneurship in South Africa. Journal of Social Sciences, 32(2), 133-142.

Guy, L., \& Liang, Z. (2012). Understanding the performance of the electric power industry in China. Asian Economic Papers, 11(2), 62-92.

Hair, J. F., Jr., Babin, B., Money, A. H., \& Samouell, P. (2007). Fundamentos de métodos de pesquisa em administração. Porto Alegre: Bookman.

Herrington, M. (2011). Entrepreneurship: how can obstacles be overcome? In M. Mbeki (Ed.), Advocates for change (pp. 115-135). Johannesburg: Picador Africa.

Julien, P. A. (2010). Empreendedorismo regional e economia do conhecimento. São Paulo: Saraiva.

Kale, S. S. (2004). Current reforms: the politics of policy change in India's electricity sector. Pacific Affairs, 77(3), 467-491.

Khanka, S. S. (2010). The impact of government policies on the development of regional entrepreneurship: an exploratory study in the north-eastern region of India. South Asian Journal of Management, 17(4), 37-59.

Khanna, M., \& Zilberman, D. (1999). Barriers to energy-efficiency in electricity generation in India. Energy Journal, 20(1), 25-41.

Mahadea, D. (2012). Prospects of entrepreneurship to the challenge of job creation in South Africa. Journal of Developmental Entrepreneurship, 17(4), 1-17. doi: 10.1142/S1084946712500203

Malhotra, N. K. (2006). Pesquisa de marketing: uma orientação aplicada (4a ed.). Porto Alegre: Bookman.

Matsnev, O. O. (2006). Venture entrepreneurship: international experience and Russian practice. Problems of Economic Transition, 49(8), 33-43. doi: 10.2753/PET1061-1991490802

McCarthy, D. J., Puffer, S. M., \& Shekshnia, S. V. (1993). The resurgence of an entrepreneurial class in Russia. Journal of Management Inquiry, 2(2), 125-137. doi: 10.1177/105649269322002

Minayo, M. C. S., \& Sanches, O. (1993). Quantitativo-qualitativo: oposição ou complementaridade? Caderno de Saúde Pública, 9(3), 239-262. doi: 10.1590/S0102-311X1993000300002

Nasra, R., \& Dacin, M. (2010). Institutional arrangements and international entrepreneurship: the state as institutional entrepreneur. Entrepreneurship: Theory \& Practice, 34(3), 583-609. doi: 10.1111/j.1540-6520.2009.00354.x

Ninan, K. N. (2012). Electricity pricing reforms in Karnataka, India: an appraisal. Journal of Institute of Public Enterprise, 35(3/4), 67-80.

North, D. C. (1990). Institutions, institutional change, and economic performance. Cambridge, MA: Harvard University Press.

O’Neill, J. (2001). Building better global economic BRICs (Global Economics Paper no 66). New York, Goldman, Sachs \& Co. 
O’Neill, J. (2011, January 6). South Africa as a BRIC? Investment Week. Retrieved from http://www.investmentweek.co.uk/investment-week/opinion/1935362/jim-oneill-south-africabric\#ixzz1pZRYzno5

Pama, A. (2004). A new tax system for a new South Africa. International Tax Review, 15(5), 1-3.

Pautasso, D. (2010). A África no comércio internacional do Grupo BRIC. Boletim Meridiano 47, $11(120), 54-59$.

Pedroso, J. P. P., Massukado-Nakatani, M. S., \& Mussi, F. B. (2009). A relação entre o jeitinho brasileiro e o perfil empreendedor: possíveis interfaces no contexto da atividade empreendedora no Brasil. Revista de Administração Mackenzie, 10(4), 100-130. doi: 10.1590/S1678-69712009000400006

Peng, M. W. (2009). Global business. Cincinnati, OH: South-Western Cengage Learning.

Peng, M. W., Sunny Li, S., Pinkham, B., \& Hao, C. (2009). The institution-based view as a third leg for a strategy tripod. Academy of Management Perspectives, 23(3), 63-81. doi: 10.5465/AMP.2009.43479264

Peng, M. W., Wang, D., \& Jiang, Y. (2008). An institution-based view of international business strategy: a focus on emerging economies. Journal of International Business Studies, 39(5), 920-936. doi: 10.1057/palgrave.jibs. 8400377

Pittman, R., \& Zhang, V. (2010). Electricity restructuring in China: how competitive will generation markets be? Singapore Economic Review, 55(2), 377-400. doi: 10.1142/S021759081000378X

Pohlmann, M. C. (2009). Análise de conglomerados. In L. J. Corrar, E. Paulo, \& J. M. Dias Filho (Eds.), Análise multivariada para os cursos de administração, ciências contábeis e economia (pp. 324388). São Paulo: Atlas.

Puffer, S. M., McCarthy, D. J., \& Boisot, M. (2010). Entrepreneurship in Russia and China: the impact of formal institutional voids. Entrepreneurship Theory and Practice, 34(3), 441-467. doi: 10.1111/j.1540-6520.2009.00353.x

Purushothaman, R. (2004). India: realizing BRICs potential (Global Economics Paper $n^{\circ} 109$ ), New York, Goldman, Sachs \& Co.

Raman, N. (2010). Technology and entrepreneurship: how India can lead in creating a sustainable world future. Journal of Technology Management for Growing Economies, 1(2), 71-85.

Scott, W. R. (1995). Institutions and organizations. Thousand Oaks, CA: Sage.

Tseng, C. (2011). Special issue on restructuring and sustainable development for China's electric power industry. Journal of Energy Engineering, 137(3), 115. doi: 10.1061/(ASCE)EY.19437897.0000050

Volkov, V. (1999). Violent entrepreneurship in post-communist Russia. Europe-Asia Studies, 51(5), 741-754. doi: 10.1080/09668139998697

Wengle, S. (2012). Post-soviet developmentalism and the political economy of Russia's electricity sector liberalization. Studies in Comparative International Development, 47(1), 75-114. doi: 10.1007/s12116-011-9096-x

Wernerfelt, B. (1984). A resource-based view of the firm. Strategic Management Journal, 5(2), 272280. doi: 0143-2095/84/020171-10

Williamson, O. E. (1975). Markets and hierarchies: analysis and antitrust implications. New York: Free Press. 
Williamson, O. E. (1985). The economic institutions of capitalism. New York: Free Press.

Williamson, O. E. (1996). The mechanisms of governance. New York: Oxford University Press.

Williamson, O. E. (2005). Transaction cost economics and business administration. Scandinavian Journal of Management, 21(1), 19-40. doi: 10.1016/j.scaman.2005.02.002

Williamson, O. E. (2010). Transaction cost economics: the origins. Journal of Retailing, 86(3), 227231. doi: 10.1016/j.jretai.2010.07.006

Wilson, D. (2003). Dreaming with BRICs: the path to 2050 (Global Economics Paper n 99), New York, Goldman, Sachs \& Co.

World Bank. (2013). Doing Business 2013: smarter regulations for small and medium-size enterprises. Washington, DC: Author. doi: 10.1596/978-0-8213-9615-5

Yeh, E. T., \& Lewis, J. I. (2004). State power and the logic of reform in China's electricity sector. Pacific Affairs, 77(3), 437-465.

Yueh, L. (2012). Legal development, financial repression, and entrepreneurship in a marketizing economy. The Chinese Economy, 45(4), 39-82.

\section{Dados dos Autores}

Diego de Queiroz Machado

Av. Washington Soares, 1321, Bl. P, Edson Queiroz, 60811-905, Fortaleza, CE, Brasil. E-mail: diegoqueirozm@ yahoo.com.br

Gleison Mendonça Diniz

Av. Washington Soares, 1321, Bl. P, Edson Queiroz, 60811-905, Fortaleza, CE, Brasil. E-mail: gleisondiniz@uol.com.br

Mario Henrique Ogasavara

Rua Doutor Âlvaro Alvim, 123, Bl. C, Vila Mariana, 04018-010, São Paulo, SP, Brasil. E-mail: mario.ogasavara@espm.br

Fátima Regina Ney Matos

Av. Washington Soares, 1321, Bl. P, Edson Queiroz, 60811-905, Fortaleza, CE, Brasil. E-mail: fneymatos@ unifor.br 